Original Artide

\title{
Physicochemical and Rheological Properties and Microstructure of Canola oil as Affected by Monoacylglycerols
}

\author{
Mehdi Naderi ${ }^{1}$, Jamshid Farmani ${ }^{1 *}$, Ladan Rashidi ${ }^{2}$ \\ 1- Department of Food Science and Technology, Faculty of Agricultural Engineering, Sari Agricultural Sciences and Natural Resources University, Sari, \\ Iran. \\ 2- Faculty of Food Industry and Agriculture, Standards Research Institute, Iranian National Standards Organization, Karaj, Iran.
}

\section{A B S T R A C T}

Background and Objectives: Canola oil is very low in saturated fatty acid $(\sim 8 \%)$, which makes it suitable for application as dressing for salad. Canola oil is liquid, thus its application in the production of margarine and shortening is limited. The present study provides information about the effects of monoacylglycerols (MAG) as the structuring agent on physical, microstructure and rheological properties of canola oil.

Materials and Methods: Canola oil was added 0.5, 3.0 and 5.0\% MAGs. Fatty acid composition, iodine value (IV), slip melting point (SMP), solid fat content (SFC), rheological properties (viscose, elastic and complex moduli, complex viscosity and $\tan \delta$ ) and its microstructure by polarized light microscopy (PLM) were evaluated.

Results: MAGs at $0.5 \%$ concentration, did not affect the saturated fatty acid (SFA) content; however, at 3 or $5 \%$ concentrations, SFA content increased $(P<0.05)$. MAGs increased solid fat content (SFC) of fats proportional to MAG content. At $0.5 \%$ concentration, MAGs had no effect on SMP, but at higher concentrations, SMP increased with MAGs concentration. With the increase of MAGs concentration, the induction period of crystallization decreased and crystallization rate increased at all temperatures. In spite of the decrease of $\tan \delta$ by MAGs addition, samples containing higher MAG concentration had higher viscose, elastic and complex moduli and complex viscosity. PLM images indicated that MAG addition resulted in an increased hardness of canola oil.

Conclusions: Canola oil structured with MAGs, can find its application in the production of liquid margarines and shortenings suitable for the use in bakery.

Keywords: Canola oil, Monoacylglycerols, Microstructure, physicochemical properties, Rheological properties

\section{Introduction}

Physicochemical and rheological properties of oils with liquid nature can be modified using structuring agents. Structuring agents are able to create a solid state in oil matrix by forming a 3D network, capable of entrapping oil. Such compounds decrease the induction time of crystallization by intensifying the formation of crystal nuclei (1). The main advantage of such ingredients is the solidification of liquid oils without a noticeable increase in saturated fatty acids (SFA) and trans fatty acids (TFA) content (2). Mostly used structuring agents include diacylglycerols, monoacylglycerols (MAGs) (3, 4), waxes (5), fatty acid and fatty alcohol (6), lecithin and sorbitan teri-stearate (7). Among them, MAGs are the most interesting due to their lower price and ability to decrease serum insulin and triacylglycerol (8). Accordingly, MAGs has been used as structuring agent in the modification of different oils and fats including palm oil (9), milk fat (10), palm olein, coconut oil (11) and chicken fat (4).

Properties of MAG-structured oils are generally different from their initial oils. Bin Sintang et al. investigated the oil-structuring properties of MAGs and phytosterols mixtures and expressed that fats structured using these mixtures had the predominant 
solid-like structure $\left(\mathrm{G}^{\prime}>\mathrm{G}^{\prime \prime}\right)$ (3). Lupi et al. reported that at MAG concentrations less than $2 \mathrm{wt} \%$, the onset of crystallization increases with the number of saturated components in the fat mixture, whereas at higher MAG concentrations, the onset of crystallization is only dependent on the MAG concentration (12). Saturated fatty acid content of canola oil is very low $(\sim 8 \%)$, thus this oil can be introduced as salad oil (13). Having a high amount of oleic acid (around 60\%), canola oil is classified among the monounsaturated vegetable oils. This oil has a relatively high content of tocopherols (700$1200 \mathrm{mg} / \mathrm{kg}$ ), mainly $\gamma$ and $\alpha$ - tocopherols (13). These characteristics make it desirable in terms of both oxidative stability and low saturated fatty acid content. However, due to its liquid state, canola oil could not be used directly in the production of fat products such as margarine or shortening. On the other hand, the effect of MAGs on properties of canola oil has not been investigated, yet. Thus, in the present research, we evaluated the effects of MAGs as structuring agent on microstructure, rheology and physicochemical properties of canola oil. Results of this study may be helpful in the development of low saturated fat products from structured canola oil.

\section{Materials and Methods}

\section{Material}

Refined, bleached and deodorized canola oil with traditional name of Kimball (Koorosh Co, Iran) was purchased from a local market in Tehran (Iran) and stored at refrigerator $\left(5{ }^{\circ} \mathrm{C}\right)$ until used. MAGs (composed of 90-95\% 1-MAG, 3-5\% 2-MAG, 2-4\% DAG, less than $1 \%$ glycerol, and free fatty acids) with the commercial name of BLANID DMAG 1600 was purchased from Farzan Rad Co. (Tehran, Iran). Other chemicals were obtained from Merck Co. (Darmstadt, Germany).

Sample Preparation: MAG was dissolved in canola oil at $60^{\circ} \mathrm{C}$ with slow agitation and stored in a refrigerator until analysis. Before analysis, samples were melted at $60^{\circ} \mathrm{C}(4)$.

Fatty Acid Profile Analysis: According to the American Oil Chemists' Society (AOCS) (14) Ce 266 method, Fatty acid methyl esters were prepared, subsequently analyzed by a Trace GC (Yanglin, South Korea) as described by AOCS Ce 1-91 method (14). A BPX-70 capillary column $(60 \mathrm{~m} \times 0.25 \mathrm{~mm}$ $\times 0.25 \mathrm{~mm}$, Restek, Bellefonte, PA, USA) and a flame ionization detector, was used to resolve and detect fatty acid methyl esters. A split ratio of 1:80 was used for Injection. Nitrogen with a flow rate of $0.8 \mathrm{ml} / \mathrm{min}$ was applied as a carrier gas. Initially, the oven temperature was set at $175{ }^{\circ} \mathrm{C}$ for $30 \mathrm{~min}$, subsequently programmed to rise to $200^{\circ} \mathrm{C}$ with the rate of $1.5^{\circ} \mathrm{C} / \mathrm{min}$. The detector temperature was $250^{\circ} \mathrm{C}$.

Iodine Value: Iodine value (IV) was determined computationally according to the AOCS official method Cd 1c-85 (14).

Slip Melting Point: Slip melting point (SMP) was measured according to the AOCS open capillary tube method CC 3-25 (14).

Solid Fat Content: Using a pulsed nuclear magnetic resonance spectroscope (Minispec mq20, Bruker, Hamburg, Germany), solid fat content (SFC) of samples at $10,20,30,40$ and $50{ }^{\circ} \mathrm{C}$ was measured according to the AOCS method $16 \mathrm{~b}-93$ (14).

Kinetics of Crystallization: The induction period of crystallization (IP $\left.\mathrm{P}_{\text {Crys }}\right)$ and crystallization rate ( Rate $_{\text {Crys }}$ ) of canola oil samples were determined at 25, 35 and $45{ }^{\circ} \mathrm{C}$ according to the methods of Farmani et al. (15) and Farmani and Gholitabar (16). In summary, samples were molten at $80{ }^{\circ} \mathrm{C}$ for 15 min and filled into SFC tubes $(180 \times 110 \mathrm{~mm})$ to a height of $3 \mathrm{~cm}$. Then, samples were put in a water bath at the desired temperature and the SFC was read with 1-minute intervals till no incremental trend was seen. $\mathrm{IP}_{\mathrm{Crys}}$ and Rate $\mathrm{Crys}_{\mathrm{s}}$ of canola oil samples were determined at 25,35 and $45{ }^{\circ} \mathrm{C}$. For this purpose, the data were fitted with the modified Gompertz equation (Eq. 1) and $\mathrm{IP}_{\mathrm{Crys}}$ and Rate Crys $_{\text {re }}$ were calculated using the equations 2 and 3 , respectively. $y=A+C e^{-e^{-B(t-M)}}$

In which, $\mathrm{A}$ is the asymptotic $\mathrm{Y}$ (Crystallization Content) as $\mathrm{t}$ (Time) decreases indefinitely, $\mathrm{C}$ is the asymptotic $\mathrm{Y}$ that occurs as $\mathrm{t}$ increases indefinitely, and $\mathrm{B}$ is the relative crystallization rate at $\mathrm{M}$, where $\mathrm{M}$ is the time at which the absolute crystallization rate is maximum.

Parameters B, A, C and $\mathrm{M}$ were calculated using Sigma plot ver.12 (Systat Software Inc.,) for each crystallization curve, and $\mathrm{IP}_{\text {Crys }}$ and Rate Crys $_{\text {rys }}$ were calculated from the following equations:

$\mathrm{IP}_{\text {Crys }}=\mathrm{M}-1 / \mathrm{B}$

Rate $_{\text {Crys }}=(\mathrm{B} \times \mathrm{C}) / \mathrm{e}$

Polarized Light Microscopy: After melting the fats at $80{ }^{\circ} \mathrm{C}$, a drop (about $1 \mu \mathrm{L}$ ) was placed on a glass 
slide preheated at a constant temperature $\left(80^{\circ} \mathrm{C}\right)$ and covered with a cover glass. Slides were kept in a stove at the experiment temperatures $(5,25$ and $40^{\circ} \mathrm{C}$ ) for $24 \mathrm{~h}(4)$. Crystal microstructure of samples was investigated by means of a polarized light microscope (Olympus, model BX 50) coupled to a digital video camera (Canon, SX 30IS, Tokyo, Japan). Images were taken at $5 \mathrm{X}$ magnification (4).

Rheological Analysis: Dynamic temperature sweep tests (using a temperature ramp from 10 to $50{ }^{\circ} \mathrm{C}$ with a rate of $1{ }^{\circ} \mathrm{C} / \mathrm{min}$ at a constant frequency of 1 $\mathrm{Hz}$ ) were performed to obtain storage modulus $\left(\mathrm{G}^{\prime}\right)$, loss modulus ( $\left.\mathrm{G}^{\prime \prime}\right)$, complex modulus $\left(\mathrm{G}^{*}\right)$, damping factor $\left(\tan \delta, G^{\prime \prime} / G^{\prime}\right)$ and complex viscosity. For all samples, concentric cylinder (CC27-SN16194; $d=0$ $\mathrm{mm})$ geometry was applied and the critical temperatures were determined by using the Anton Paar Rheoplus software (Rheo-plus/32V3.21, AntonPaar, GmbH, Graz, Austria) (17).

\section{Statistical Analysis}

To analyze the data using SPSS version 16.0 (SPSS Inc. Chicago, IL, USA), One-way ANOVA was used. Significant differences were determined using the Duncan test at $P<0.05$. All data were shown as mean value \pm standard deviation of triplicate experiments.

\section{Results}

Chemical properties: Fatty acid compositions of canola oil samples structured by MAGs and control are presented in Table 1. MAG addition in the concentration of $0.5 \%$ could not increase the SFA content of canola oil; however, samples structured by 3 or $5 \%$ MAGs showed an increased SFA content $(P<0.05)$.
The unsaturation of oils is quantitatively calculated by IV, showing an increase with the increase of unsaturated fatty acids. As presented in Table 1, the IV of the structured oils with 3 or $5 \%$ MAGs decreased significantly $(P<0.05)$. As reported for SFA content, there was no significant difference between the IV of a sample containing $0.5 \%$ MAGs and canola oil $(P<0.05)$.

Physical properties: SFCs of samples at 10, 20, 30, 40 and $50{ }^{\circ} \mathrm{C}$ are shown in Table 2 . As can be seen, canola oil had no SFC at all measured temperatures. MAG-structured canola oil samples present increased SFC (proportional to the MAG content) in comparison with the canola oil.

The SMPs of structured fats are mentioned in Table 2. As shown in this Table, MAGs at $0.5 \%$ concentration did not have any effect on SMP of canola oil. However, at higher concentrations, the MAGs were able to increase the SMP of samples $(P<$ $0.05)$.

Considering the crystallization properties, canola oil and the sample with $0.5 \%$ MAGs did not crystallize at the measured temperatures. However, structured fats containing 3.0 or $5.0 \%$ were rapidly crystallized at 25 and $35^{\circ} \mathrm{C}$ (Fig.1A, B). Structured fat with $5.0 \%$ MAGs crystallized even at $45{ }^{\circ} \mathrm{C}$ whereas the concentration of $3.0 \%$ MAGs could not emerge any crystal nuclei at such a temperature (Fig.1C). MAGs accelerated the onset and rate of crystallization as the sample containing $5 \%$ MAG crystalized more rapidly than that of containing $3 \%$ MAG.

Table 1. Effect of monoacylglycerol (MAG) addition on fatty acid composition and iodine value (IV) of canola oil

\begin{tabular}{lllllllll}
\hline Samples & C14:0 & C16:0 & C18:0 & C18:1 & C18:2 & C18:3 & SFAs & IVs \\
\hline Canola oil & $0.30 \pm 0.1^{\mathrm{a}}$ & $6.9 \pm 0.1^{\mathrm{b}}$ & $3.7 \pm 0.2^{\mathrm{a}}$ & $60.5 \pm 0.1^{\mathrm{a}}$ & $19.5 \pm 0.1^{\mathrm{a}}$ & $6.7 \pm 0.1^{\mathrm{a}}$ & $10.6 \pm 0.1^{\mathrm{c}}$ & $103.8^{\mathrm{a}}$ \\
SCO 0.5\% & $0.31 \pm 0.2^{\mathrm{a}}$ & $7.2 \pm 0.1^{\mathrm{b}}$ & $3.7 \pm 0.1^{\mathrm{a}}$ & $61.0 \pm 0.1^{\mathrm{a}}$ & $19.4 \pm 0.1^{\mathrm{a}}$ & $6.6 \pm 0.1^{\mathrm{a}}$ & $11.0 \pm 0.1^{\mathrm{c}}$ & $103.0^{\mathrm{a}}$ \\
SCO 3.0\% & $0.36 \pm 0.2^{\mathrm{a}}$ & $9.4 \pm 0.1^{\mathrm{a}}$ & $3.6 \pm 0.2^{\mathrm{a}}$ & $58.6 \pm 0.1^{\mathrm{b}}$ & $18.9 \pm 0.2^{\mathrm{b}}$ & $6.4 \pm 0.2^{\mathrm{a}}$ & $13.2 \pm 0.1^{\mathrm{b}}$ & $100.1^{\mathrm{b}}$ \\
SCO 5.0\% & $0.41 \pm 0.1^{\mathrm{a}}$ & $11.3 \pm 0.1^{\mathrm{a}}$ & $3.5 \pm 0.2^{\mathrm{a}}$ & $57.4 \pm 0.1^{\mathrm{b}}$ & $18.5 \pm 0.2^{\mathrm{b}}$ & $6.3 \pm 0.2^{\mathrm{a}}$ & $15.0 \pm 0.1^{\mathrm{a}}$ & $98.1^{\mathrm{c}}$ \\
MAG & $2.5 \pm 0.1$ & $96.5 \pm 0.1^{\mathrm{a}}$ & $0.3 \pm 0.1$ & $0.3 \pm 0.1^{\mathrm{a}}$ & 0.0 & 0.0 & $99.5 \pm 0.1^{1}$ & \\
\hline
\end{tabular}

Data are presented as the means \pm SD of three replicates. Different superscript letters show significant differences in each column at $P<0.05$. SCO: structured canola oil, SFAs: Saturated fatty acids, IVs: Iodine value

Table 2. Solid fat content (SFC) and slip melting point (SMP) of structured canola oil (SCO) samples

\begin{tabular}{lcccccc}
\hline & \multicolumn{7}{c}{$\mathbf{S F C \%}$} & $\mathbf{5 0}^{\circ} \mathbf{C}$ & SMP \\
\cline { 2 - 6 } Sample & $\mathbf{1 0}^{\circ} \mathbf{C}$ & $\mathbf{2 0}^{\circ} \mathbf{C}$ & $\mathbf{3 0}^{\circ} \mathbf{C}$ & $\mathbf{4 0}^{\circ} \mathbf{C}$ & 0.0 & - \\
\hline Canola oil & 0.0 & 0.0 & 0.0 & 0.0 & 0.0 & - \\
SCO 0.5\% & $0.40 \pm 0.3^{\mathrm{c}}$ & $0.21 \pm 0.3^{\mathrm{c}}$ & 0.0 & 0.0 & 0.0 & $31.0 \pm 0.5^{\mathrm{b}}$ \\
SCO 3.0\% & $2.68 \pm 0.3^{\mathrm{b}}$ & $2.05 \pm 0.3^{\mathrm{b}}$ & $1.6 \pm 0.3^{\mathrm{b}}$ & $1.14 \pm 0.2^{\mathrm{b}}$ & $0.37 \pm 0.3^{\mathrm{a}}$ & $3^{\mathrm{a}}$ \\
SCO 5.0\% & $4.70 \pm 0.2^{\mathrm{a}}$ & $4.1 \pm 0.3^{\mathrm{a}}$ & $3.20 \pm 0.3^{\mathrm{a}}$ & $2.06 \pm 0.3^{\mathrm{a}}$ & $1.11 \pm 0.2^{\mathrm{b}}$ & $38.5 \pm 0.7^{\mathrm{a}}$ \\
\hline
\end{tabular}

Data are presented as the means \pm SD of three replicates. Different superscript letters show significant differences in each column at $\mathrm{P}<0.05$. 


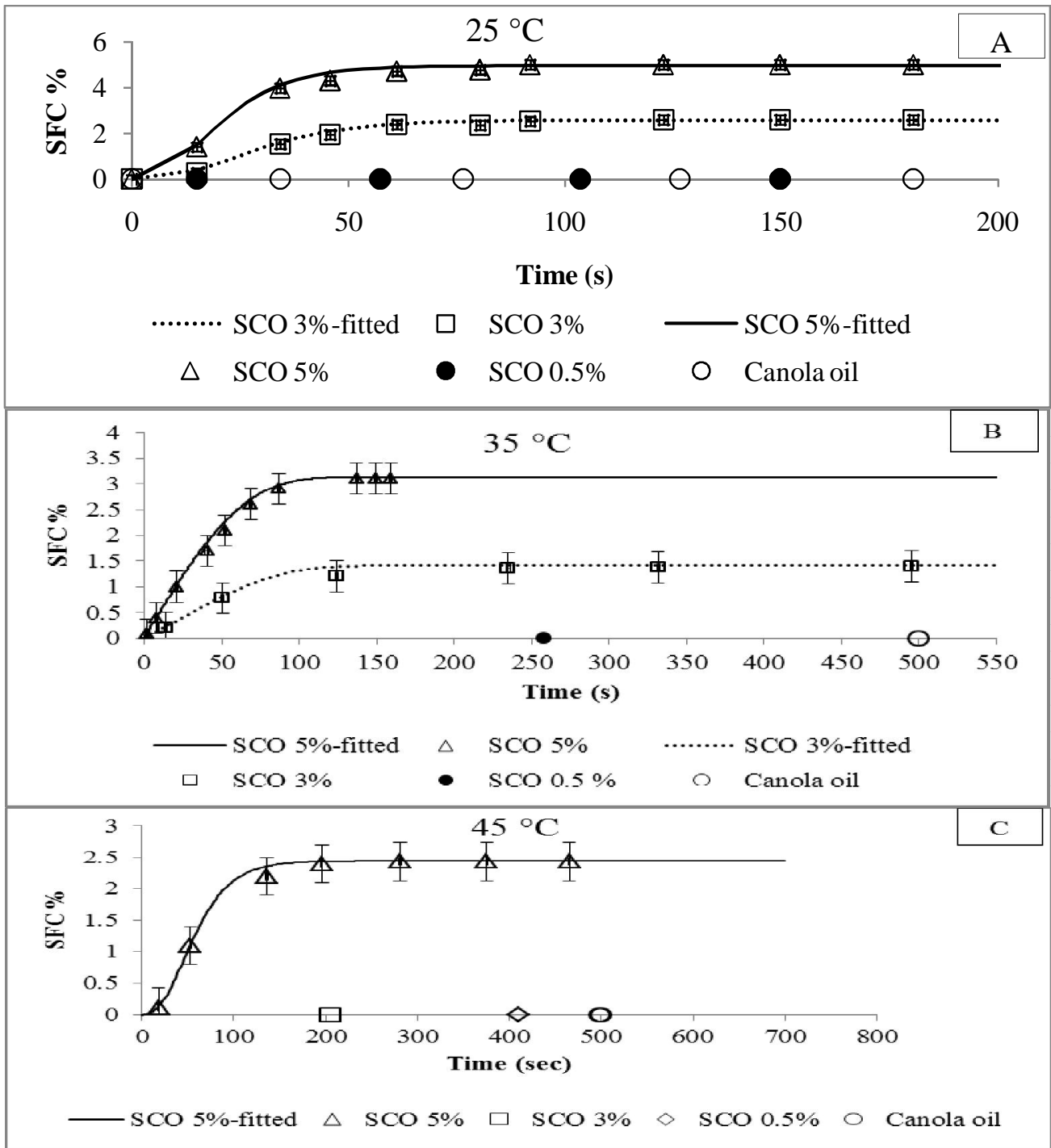

Fig. 1 Crystallization curve of canola oil samples structured by monoacylglycerol (MAG) AT 25 (A), 35 (B) AND $45^{\circ} \mathrm{C}$ (C). Markers and lines represent experimental and fitted (predicted by the modified Gompertz function) data; SCO: Structured canola oil, SFC: Solid Fat Content.

Using the modified Gompertz equation (Eq. 1, 2, 3 ), the $\mathrm{IP}_{\text {cryst }}$ and crystallization rate of samples were calculated (Table 3). As shown in Table 3, IP cryst decreased and crystallization rate increased at all temperatures as MAG concentration increased.

Visual appearances of structured canola oil are presented in Fig.2. For this purpose, samples were melted at $80^{\circ} \mathrm{C}$ and subsequently crystallized for $2 \mathrm{~h}$ at room temperature (about $25{ }^{\circ} \mathrm{C}$ ). As can be found from Fig. 2 A, while the canola oil is liquid, structured fats with 3.0 or $5.0 \%$ MAGs have solid texture and do not flow by inverting test tubes. However, MAG addition at the $0.5 \%$ concentration could not create a solid state into the canola oil; it only emerged a few crystal nuclei.
Table 3. IP of crystallization ( $\mathrm{IP}_{\mathrm{CRYST}}$ ) and crystallization rate data of structured canola oil (SCO) SAMPLES determined at 25,35 and $45^{\circ} \mathrm{C}$

\begin{tabular}{lcc}
\hline \multirow{2}{*}{ Samples/Temperature } & \multicolumn{2}{c}{ Crystallization kinetics } \\
\cline { 2 - 3 } & $\mathrm{IP}_{\text {Cryst (Second })}$ & crystallization Rate $(1 / \mathrm{min})$ \\
\hline $25{ }^{\circ} \mathrm{C}$ & - & - \\
Canola oil & - & - \\
$\mathrm{SCO} 0.5 \%$ & $9.7 \pm 0.06^{\mathrm{a}}$ & $0.1 \pm 0.06^{\mathrm{a}}$ \\
$\mathrm{SCO} 3.0 \%$ & $6.6 \pm 0.06^{\mathrm{b}}$ & $0.08 \pm 0.03^{\mathrm{b}}$ \\
$\mathrm{SCO} 5.0 \%$ & & \\
& - & - \\
$35{ }^{\circ} \mathrm{C}$ & - & - \\
Canola oil & $84.5 \pm 0.06^{\mathrm{a}}$ & $0.01 \pm 0.06^{\mathrm{b}}$ \\
SCO 0.5\% & $18.8 \pm 0.06^{\mathrm{b}}$ & $0.06 \pm 0.08^{\mathrm{a}}$ \\
SCO 3.0\% & & \\
SCO 5.0\% & - & - \\
$45{ }^{\circ} \mathrm{C}$ & - & - \\
Canola oil & - & - \\
SCO 0.5\% & $18.9 \pm 0.07^{\text {a }}$ & $0.03 \pm 0.06^{\mathrm{a}}$ \\
SCO 3.0\% & & \\
SCO 5.0\% & & \\
\hline Data are presented as the means \pm SD of three replicates. Different superscript \\
letters show significant differences in each temperature/column at $P<0.05$.
\end{tabular}




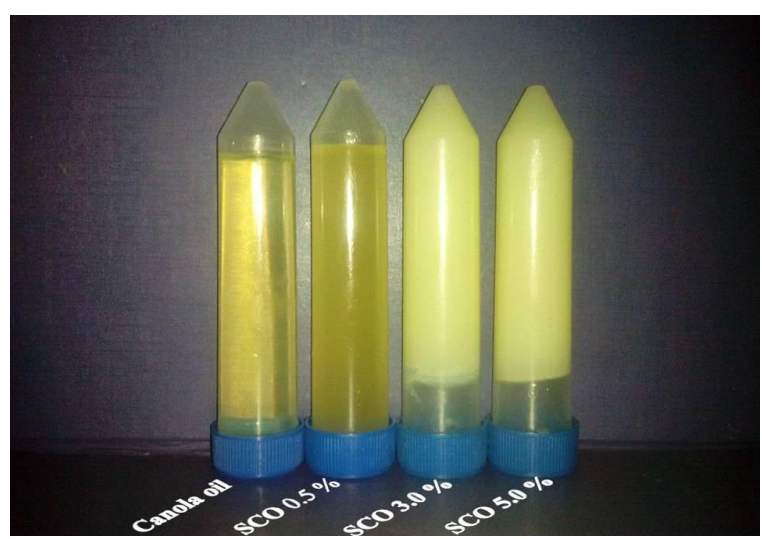

Fig. 2. The visual appearance of structured canola oil (SCO) samples crystallized at room temperature for $2 \mathrm{~h}$. SCO: Structured canola oil

Polarized light microscopy (PLM) was used to observe the microstructure of structured fats. The fat microstructure is affected by its composition and crystallization regime. As shown in Fig. 3, at lower temperatures, the number and size of clusters are increased and decreased, respectively. In fact, fat crystals do not have enough time to grow more at lower temperatures, thus decreasing cluster size and increasing cluster number. Canola oil with the liquid state had no crystals at all the measured temperature (as also reported for SFC data). Adding MAGs at 0.5 $\%$ concentration increased somewhat the crystallized fat at $25{ }^{\circ} \mathrm{C}$; however, no crystal was observed at 40 ${ }^{\circ} \mathrm{C}$, yet. The increase of MAGs concentration leads to a denser structure with higher amounts of crystallized fat at all the measured temperatures. Crystalized samples containing 3 or $5 \%$ MAGs, showed crystal shape at $40{ }^{\circ} \mathrm{C}$; however, the number of crystals was lower compared to the lower temperatures.
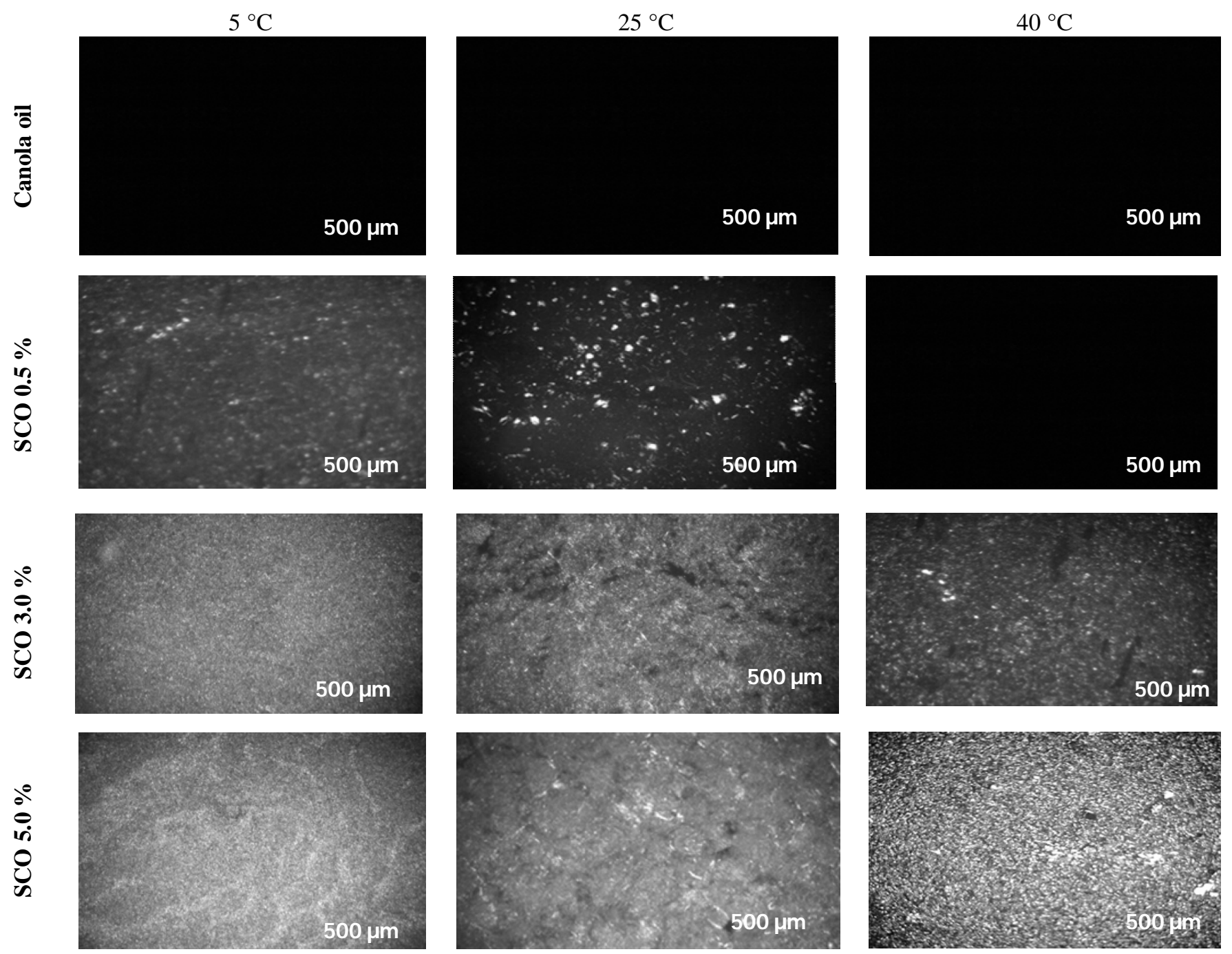

Fig. 3. Microstructure Images of structured canola oil at 5,25 and $40^{\circ} \mathrm{C}$ with the magnification of $5 \mathrm{x}$ (B). 
Rheological properties: In temperature sweep test, the rheological properties of the product are described as a function of temperature at a fixed frequency. The changes in $G^{\prime}, G^{\prime \prime}, \operatorname{Tan} \delta, \mathrm{G}^{*}$ and $\eta^{*}$ moduli of structured fats at $10-50{ }^{\circ} \mathrm{C}$ are shown in Fig.4.
As can be seen in Fig. 4A, MAG addition to canola oil caused an increase in both elastic modulus $\left(G^{\prime}\right)$ and viscose modulus $\left(G^{\prime \prime}\right)$. The $G^{\prime \prime}$ and $G^{\prime}$ moduli curves of the sample containing 5.0 \% MAGs were closer to each other than those of the sample containing $3 \%$ MAGs.
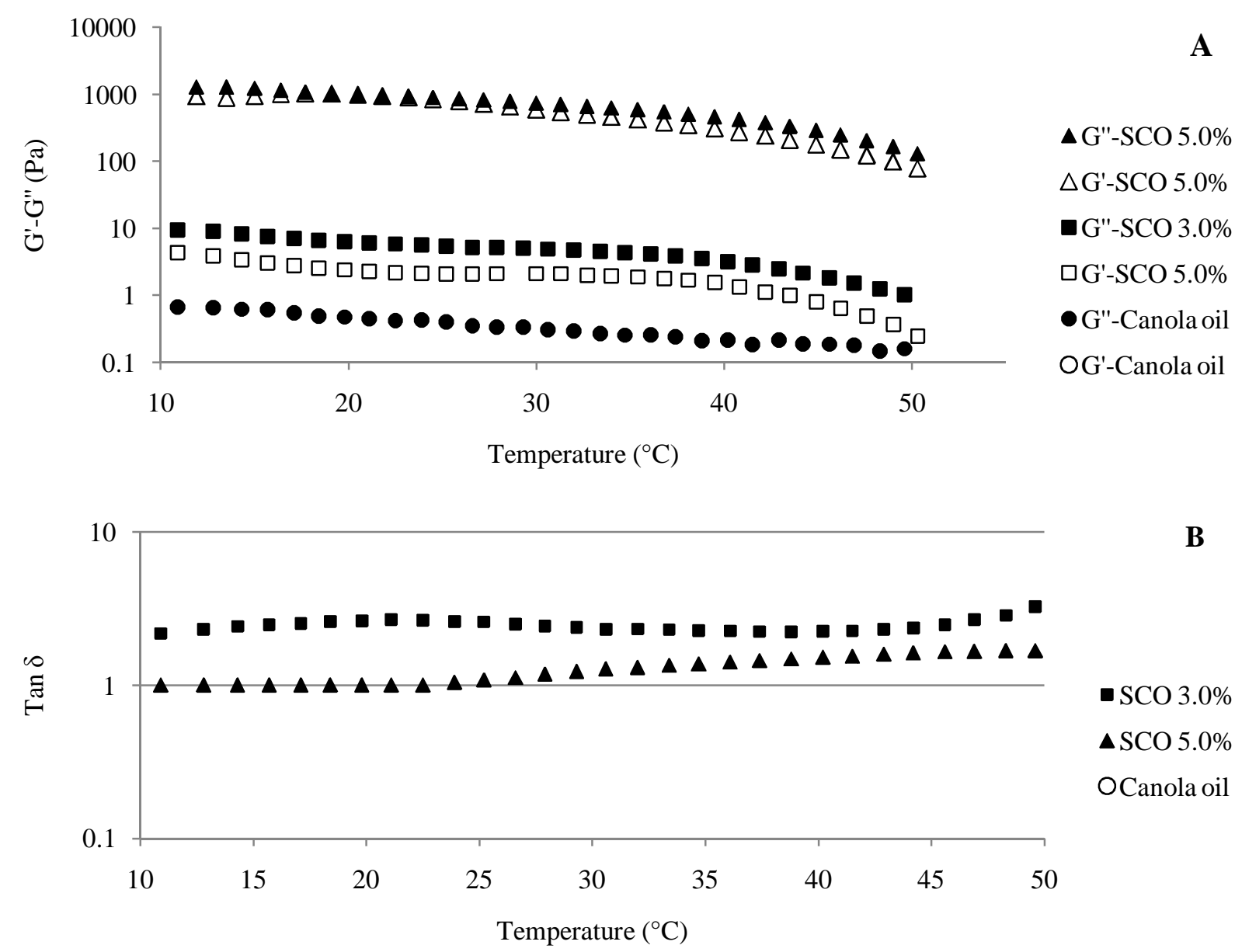

$\mathbf{B}$

- $\mathrm{SCO} 3.0 \%$

$\triangle \mathrm{SCO} 5.0 \%$

OCanola oil

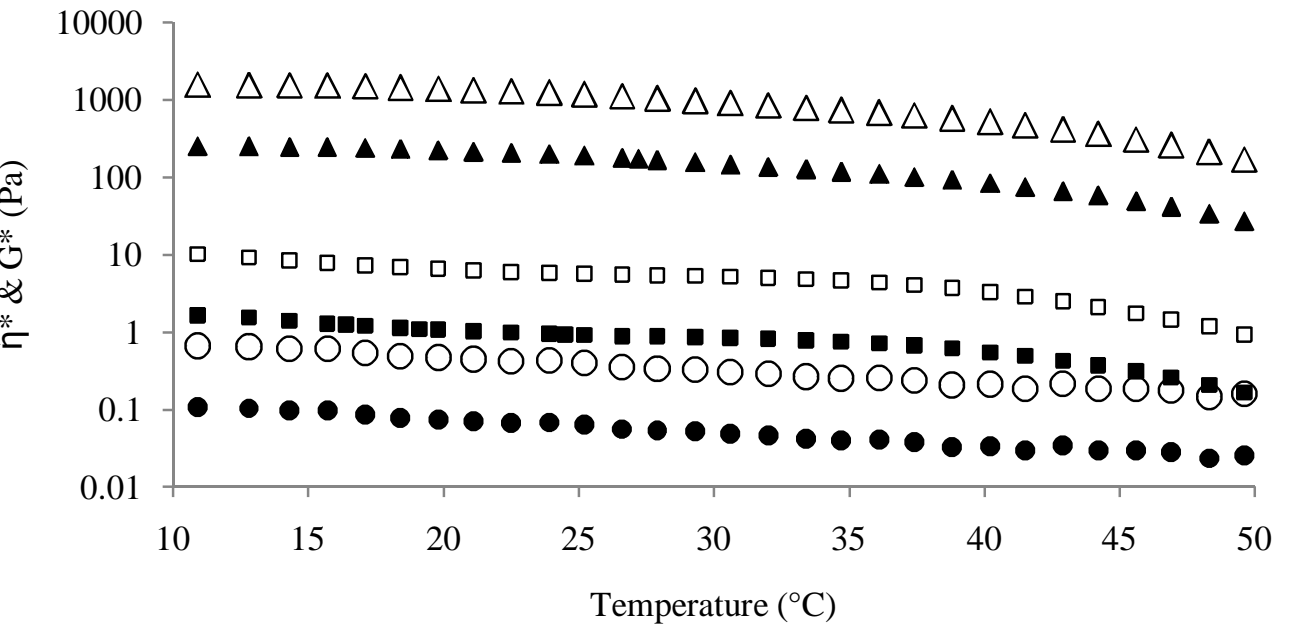

C

$\triangle \mathrm{G}^{*}$-SCO $5.0 \%$

$\triangle \eta^{*}-\mathrm{SCO} 5.0 \%$

$\square \mathrm{G}^{*}-\mathrm{SCO} 3.0 \%$

- $\eta *$-SCO $3.0 \%$

OG*-Canola oil

- $\eta^{*}$-Canola oil

Fig. 4. Rheological properties of structured canola oil (SCO) determined by temperature sweep test from 10 to $50{ }^{\circ} \mathrm{c}$. A, viscose and elastic moduli curves; B, $\tan \delta$ moduli curves; C, complex modulus $(\square)$ and complex viscosity $\left(\mathrm{G}^{*}\right)$ curves. 
Tan $\delta$ curves of MAG-containing samples are presented in Fig.4B. As shown in Fig.3B, structured canola oil samples showed a constant $\tan \delta$ at around 10 to $20^{\circ} \mathrm{C}$, but increased thereafter.

As can be seen in Fig.3C, the addition of MAGs led to the increase of complex modulus $\left(\mathrm{G}^{*}\right)$ of structured fats. In fact, with the increase of $G^{\prime \prime}$ and $G^{\prime}$, the $\mathrm{G}^{*}$ increased markedly.

As shown in Fig.4C, MAG addition to the canola oil increased the complex viscosity $\left(\eta^{*}\right)$ as observed for $G^{\prime \prime}, G^{\prime}$ and $G^{*}$.

\section{Disc ussion}

The increase in the SFA of structured fats could be explained by the high SFA content of the added MAGs $(99.5 \%$, Table 1). This result was not in accordance with that of Maruyama et al. (11). They reported that the addition of MAGs at a concentration of 1 or $3 \%$ could not alter the SFA content of palm olein and coconut oils. Such opposite results could be explained by the differences between the fatty acid compositions of MAGs and also the MAGs content applied in the two studies. Maruyama et al. (11) in their research used two kinds of MAGs (EM1 and EM2). The SFAs of EM1 and EM2 were 24.9 and 99.7, respectively.

MAG addition decreased the IV of samples by an increase of their SFA content (Table 1). This finding was not accordance with the Maruyama et al. (11). Their research indicated no significant difference in IV as added EM1 and EM2 to palm olein and coconut oil. Such opposite results could be explained by the percentage of added MAGs and also the different SFA of applied MAGs. In terms of IV and the fatty acid composition of structured canola oil, it could be concluded that the MAGs impact on oil is strongly dependent on its SFA and the fatty acids composition of oil as added by MAGs.

SFC determines the hardness of fats at temperatures lied between refrigerator and month temperature. In fact, MAGs increase the SFC of the sample by improving the crystal network formation. As shown in Table 2, with the increase of the MAG concentration in samples, SFC resistance to temperature was enhanced $(P<0.05)$. Our finding indicated that MAGs, due to having high SFA are able to increase the SFC of canola oil. In this context, Mardani et al. (18) reported that palm olein partial acylglycerols (composed of 3.5-11.2\% MAGs and $39-42.2 \%$ DAGs) had higher SFC than palm olein. Foubert et al. (10) also expressed that adding MAGs at a concentration of $0.5 \%$, were not able to increase the SFC of milk fat.

As mentioned before, samples having higher MAG concentrations showed higher SMPs (Table 2). The SMP increase can be attributed to the higher SFA content and the formation of crystalline networks as result of MAGs addition. In fact, the melting point of acylglycerols increases as the degree of esterification decreases. This may be due to the ease of fatty acid chain arrangement and the strength of the hydrogen bonding of the hydroxyl groups (19). In addition, the free hydroxyl groups of MAGs are able to form a crystal network via hydrogen bonds and trap the liquid phase in the network $(1,20)$.

As shown in Fig.1, under the isothermal condition, crystallization curves of structured fats show three separate phases containing lag, exponential and stationary phase. The lag phase, the time needed for a fat solution to nucleate, shows the induction period of crystallization ( $\left(\mathrm{IP}_{\text {cryst }}\right)$; the exponential phase indicates the rate of nucleation; finally, the stationary phase at which the number of crystal nuclei is not increased anymore, shows the max crystalline fat achievable at a given temperature. These results indicate that the MAGs act as a driving force of crystallization (20). In fact, MAGs, throughout heterogeneous nucleation, acts as a foreign nucleating site; therefore, it is able to decrease the time needed for nucleation. Although the exact mechanisms of heterogeneous nucleation are not understood, it is said that the interactions at the interface between the supersaturated fluid and the solid particle results in a local ordering of the molecules of the crystallizing species; thus, the energy needed for the formation of the stable nucleus is decreased (21).

PLM is a well-known method to visualize the crystal seeds of fats (22). Fat crystals are bright between two crossed polarized filters due to having the birefringence, whereas the oils with the state of thoroughly liquid present a dark sheet. With the intensifying of crystallization mechanism by MAGs, structured fat had denser texture compared to canola oil (having totally liquid nature) as result of an increase in SFC (Fig. 2 and 3). The reported results are similar to the results of Naderi et al. (4), Maruyama et al. (11) and Basso et al. (9). They reported that MAG addition (with high SFA content) 
resulted in more crystal number and more resistance to the temperature effects.

$G^{\prime \prime}$ and $G^{\prime}$ are measures of the energy dissipated and the energy stored in a material, respectively, in which a deformation has been imposed (23). These results evidenced that at higher concentrations of MAGs, $G^{\prime}$ modulus increases more. The $G^{\prime \prime}$ and the $G^{\prime}$ moduli of structured fats decreased with the increase of temperature (Fig.4 A), this may be due to the formation of stronger crystal networks. This trend was slower for the fat containing higher MAG content. A similar situation was also observed for SFC curves. Such results were also observed by Lupi et al. (12) for MAG-containing olive oil.

Tan $\delta$ is the ratio of viscous (G") to elastic modulus $\left(\mathrm{G}^{\prime}\right)(23)$. The value of $\delta$ lies between $0^{\circ}$ and $90^{\circ} . \delta$ is equal to $0^{\circ}$ for a completely elastic material and $90^{\circ}$ for a purely viscous liquid. There are some values of the $\delta$ between $0^{\circ}$ and $90^{\circ}$ for viscoelastic lipids, showing both viscous and elastic properties. The decrease of $\tan \delta$ values $(\tan \delta<1)$ is indicative of a transformation from a liquid-like behavior to a more solid-like behavior. In fact, the increase in temperature caused the G" modulus to be increased, therefore, $\tan \delta$ decreased and the liquidlike behavior overcame. Because of lack of $G^{\prime}$ modulus (being ideal viscose) in canola oil, $\tan \delta$ could not be calculated for that (Fig.4B). The cross over phenomena which is the temperature at which phase transition occurs (tan $\delta$ become more than 1), was only seen in the sample containing $5 \%$ MAGs. Such a result can be attributed to the higher $G^{\prime}$ modulus and SMP of structured fat containing $5 \%$ MAGs than those containing $3 \%$ MAGs.

The complex modulus $\left(\mathrm{G}^{*}=\sqrt{\left(\mathrm{G}^{\prime}\right)^{2}+\left(\mathrm{G}^{\prime \prime}\right)^{2}}\right)$ of structured fats is illustrated in Fig.4C. The overall resistance to deformation (total rigidity) of a material is measured by $\mathrm{G}^{*}(23)$. In other words, the increase of MAG concentration causes an increase in fat hardness (total rigidity). $\eta^{*}$ is mathematically calculated as the complex modulus divided by angular frequency (23). $\eta^{*}$ presents the total resistance of a material to flow. In fact, MAGs led to the decrease of the fluidity (an increase of the hardness) of structured fats by enhancement of crystal network formation. Findings of $\mathrm{G}^{*}$ and $\eta^{*}$ can be attributed to the SFC increase of structured fats.
In fact, greater SFC led to an increased hardness of fats. The samples with the higher $G^{*}$ and $\eta^{*}$ had the denser structure (as can be found from PLM image). These results are in agreement with those of Lupi et al. (12) who worked on MAG-structured olive oil.

Technological Applications of Structured Canola

Oil: Structured canola oil can be used in the production of some fatty products. To investigate the application of structured fats, we compared the SFC curve of MAG-added fats with that of various types of margarines and shortenings mentioned in the literature $(21,24)$. Fats containing 3.0 or $5.0 \%$ MAGs can be used as liquid margarines. Liquid margarines have advantages such as convenient storage and pumping due to their high content of unsaturated fatty acids (24). Moreover, when used in bakery product formulation, the MAGs (from the structured oil) can form complexes with the amylose fraction of starch resulting in the production of a product with softer crumbs and longer shelf life (21). In the product such as a cookie, MAGs can increase the firmness of dough (25). MAGs are also able to prevent phase separation in oils and fats with relatively high SFA content like palm oil, chicken fat and vanaspati. Naderi et al. (4) reported that MAG application at $0.5 \%(\mathrm{w} / \mathrm{w})$ concentration could prevent phase separation in chicken fat. Totally, because of the formation of self-assembly networks by MAGs, structured fats have low SFA content and offer comparable quality characteristics to fats containing greater SFA contents $(1,4)$.

\section{Conclusion}

MAGs at $0.5 \%$ concentration, could not affect the fatty acid composition, IV, FFA, SMP, IP $\mathrm{P}_{\text {cryst }}$ and crystallization rate of canola oil. At 3 or $5 \%$ concentration, the effect of MAGs on SFA content,

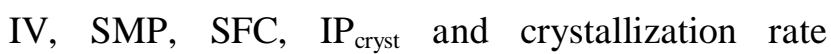
increased proportionally to the MAG content. Evaluation of rheological properties indicated that in spite of the decrease of $\tan \delta$, other properties including $G^{\prime}, G^{\prime \prime}, G^{*}$ and $\eta^{*}$ increased. Microstructure images (by PLM) confirmed the increase of crystal content by MAG addition. Canola oil structured with MAGs, can find application in the production of liquid margarines and fat products suitable for the use bakery. 


\section{Financial disclosure}

The authors declared no financial interest.

\section{Funding/Support}

This work was financially supported by Sari Agricultural Sciences and Natural Resources University.

\section{References}

1. Patel AR, Dewettinck K. Edible oil structuring: an overview and recent updates. Food \& Function. 2016;7(1):20-9.

2. Pernetti M, van Malssen KF, Flöter E, Bot A. Structuring of edible oils by alternatives to crystalline fat. Current Opinion in Colloid \& Interface Science. 2007;12(4-5):221-31.

3. Bin Sintang MD, Rimaux T, Van de Walle D, Dewettinck K, Patel AR. Oil structuring properties of monoglycerides and phytosterols mixtures. European Journal of Lipid Science and Technology. 2016:n/a-n/a.

4. Naderi M, Farmani J, Rashidi L. Structuring of Chicken Fat by Monoacylglycerols. Journal of American Oil Chemist Society. 2016;93(9):122131.

5. Toro-Vazquez JF, Morales-Rueda J, Mallia VA, Weiss RG. Relationship Between Molecular Structure and Thermo-mechanical Properties of Candelilla Wax and Amides Derived from (R)-12Hydroxystearic Acid as Gelators of Safflower Oil. Food Biophysics. 2010;5(3):193-202.

6. Schaink HM, van Malssen KF, Morgado-Alves S, Kalnin D, van der Linden E. Crystal network for edible oil organogels: Possibilities and limitations of the fatty acid and fatty alcohol systems. Food Research International. 2007;40(9):1185-93.

7. Pernetti M, van Malssen KF, Flöter E, Bot A. Structuring of edible oils by alternatives to crystalline fat. Current Opinion in Colloid \& Interface Science. 2007;12(4-5):221-31.

8. Rush JWE, Jantzi PS, Dupak K, Idziak SHJ, Marangoni AG. Acute metabolic responses to butter, margarine, and a monoglyceride gelstructured spread. Food Research International. 2009;42(8):1034-9.

9. Basso RC, Ribeiro APB, Masuchi MH, Gioielli LA, Gonçalves LAG, Santos AOd, et al. Tripalmitin and monoacylglycerols as modifiers in the crystallisation of palm oil. Food Chemistry. 2010;122(4):1185-92.

10. Foubert I, Vanhoutte B, Dewettinck K. Temperature and concentration dependent effect of partial glycerides on milk fat crystallization. European Journal of Lipid Science and Technology. 2004;106(8):531-9.

11. Maruyama JM, Soares FA, D'Agostinho NR, Goncalves MI, Gioielli LA, da Silva RC. Effects of emulsifier addition on the crystallization and melting behavior of palm olein and coconut oil. Journal of Agricultural and Food Chemistry. 2014;62(10):2253-63.

12. Lupi FR, Gabriele D, Facciolo D, Baldino N, Seta L, de Cindio B. Effect of organogelator and fat source on rheological properties of olive oil-based organogels. Food Research International. 2012;46(1):177-84.

13. Shahidi, F., Wanasundara, PKJPD. Extraction and analysis of lipids. Food Lipids:Chemistry, Nutrition, and Biotechnology. boca raton: CRC press; 2008. p. 125-58.

14. AOCS. Official Methods and Recommended Practices of the American Oil Chemists' Society. 4th ed ed: Champaign: AOCS Press.; 1996.

15. Farmani J, Safari M, Hamedi M. Application of palm olein in the production of zero-trans Iranian vanaspati through enzymatic interesterification. European Journal of Lipid Science and Technology. 2006;108(8):636-43.

16. Farmani J, Gholitabar A. Characterization of vanaspati fat produced in Iran. J Amer Oil Chem Soc. 2015;92(5):709-16.

17. Naeli MH, Farmani J, Zargaraan A. Rheological and physicochemical modification of trans-free blends of palm stearin and soybean Oil by chemical interesterification. Journal of Food Process Engineering. 2016:n/a-n/a.

18. Mardani M, Farmani, J., \& Esmaeilzadeh Kenari, R. Efficacy of some commercial lipases in hydrolysis of palm olein for production of free fatty acids and diacylglycerol oil. Journal of oil palm research. 2015;27(3):1-2.

19. Formo MW. Physical properties of fats and fatty acids. In: Swern D, editor. Bailey's Industrial Oil and Fat Products. 1. 4 ed .New York: John Wiley \& Sons; 1979. p. 177-232. 
20. Bayés-García L, Patel AR, Dewettinck K, Rousseau D, Sato K, Ueno S. Lipid crystallization kinetics roles of external factors influencing functionality of end products. Current Opinion in Food Science. 2015;4:32-8.

21. Ghotra BS, Dyal SD, Narine SS. Lipid shortenings: a review. Food Research International. 2002;35(10):1015-48.

22. Tang D, Marangoni AG. Microstructure and fractal analysis of fat crystal networks. Journal of American Oil Chemist Society.83(5):377-88.
23. Rao A. Rheology of Fluid and Semisolid Foods: Principles and Applications. 2 ed: Springer US; 2010. 482 p.

24. O'brien RD. Fats and oils: formulating and processing for applications: CRC press; 2008.

25. Goldstein A, Seetharaman, K. Effect of a novel monoglyceride stabilized oil in water emulsion shortening on cookie properties. Food Research International. 2011;44:1476-81. 